\title{
Safe abortion service and post abortion care: Understanding complications
}

\author{
Sudha Thapa*, Indira Satyal,** Kasturi Malla*** \\ Maternity Hospital, Thapathali
}

\begin{abstract}
Aim: To see if unsafe abortions are getting lesser after the establishment of comprehensive abortion care (CAC) Unit since March 2004.

Methods: Retrospective study of women admitted with complication of abortions [induced (medically/criminal) or spontaneous] during the entire ten years period after the inception of post abortion care (PAC) Unit 2095 May -2007 April); the last 3 years overlapping the service years of CAC Unit establishment.

Result: CAC and PAC units both are using manual vacuum aspiration (MVA) to procure uterine evacuation. CAC clients in the last 3 years have reached to a little less than 10,000. This is close to MVA services provided in the PAC Unit in the last 10 years amounting to 11,519. But the number $(n=3958)$ of service provided by the PAC Unit for a complete period of three years 2058-2060 (April 2001 - April 2004) showed a slight increase to $(n=4323)$ as the CAC Unit became functional during the 2061-2063 (15 th April 20042007).

The complications observed in PAC unit while providing MVA are much more than CAC unit (5.75\%: 2\%). But the nature of complication is much more serious in CAC Unit, 10 of them needing laparotomy for $20(0.02 \%)$ cases of uterine perforation.

The induced abortion rate within the hospital, three years before and during CAC services is almost similar (4.07\%: 4.34\%). Seriousness of the problem has definitely reduced during recent 3 year's period (Baisakh 2061-2063 Chaitra) i.e. 52: 34 except for an unfortunate rise in uterine perforation from 8 to 29 cases, 10 being from the CAC Unit.

Conclusion: Though the number of complicated cases of induced abortion seeking hospitalization has not changed much after inception of CAC services in the recent three years, there is definitely a decline in the admission of more serious complicated cases of induced abortion in the recent years with unfortunate rise in number of cases of uterine perforation.
\end{abstract}

\section{Introduction}

Induced abortion is a process of terminating pregnancy before the fetus becomes viable (fetus of <500gms). The Programme of Action of the International Conference on Population and Development recommends that 'In circumstances where abortion is not against the law, such abortion should be safe'.

It is needless to express that medically induced abortion is much safer than an unsafe abortion which is apt to end in complications needing hospitalized management. ${ }^{1-3}$ The World Health Organization defines unsafe abortion 'as a procedure for terminating an unintended pregnancy carried out by people lacking the necessary skills or in an environment that does not conform to minimal medical standards, or both'.

Before legalization of abortion in Nepal, women were more likely to get admitted with the complication of clandestine abortion. For this reason Post Abortion Care (PAC) Unit was established way back in May 1995

\footnotetext{
Correspondence

Sudha Thapa

Senior Consultant and coordinator of CAC*,

Senior Consultant and coordinator PAC Unit**,

and Senior Consultant and Hospital Director***

Email:sudharana@yahoo.com
} 
(Jestha 2053) at Maternity Hospital. This unit effectively enrolled all the post abortion cases admitted in the hospital, which either resulted after spontaneous or induced procedures with or without septic sequel. Therefore the unit is involved in record keeping of all the abortion related complications, besides primarily providing manual vacuum aspiration (MVA) services (by team of trained doctors and staff nurses) all round the clock, in the unit itself for the simple uncomplicated cases. That is, handling of post abortion cases where the uterine size is up to $12-14$ weeks at the time of admission or if the hemoglobin (Hb) level is $\geq 7 \mathrm{gm} \%$. Whereas more complex cases with the features of infection/ sepsis, uterine or bowel perforation, disseminated intravascular coagulation (DIC), acute renal failure (ARF), severe anemia needing blood transfusion were admitted in the wards. They were treated according to the nature of complications or taken to Minor or Major Operation Theater whenever operative interventions by dilatation and curettage (D\&C) or emergency laparotomy were needed.

Exceptions were laid in special circumstances when they could be brought back from the wards to undergo the MVA procedure in the PAC Unit in the absence of other underlying complications; once they were considered fit with the improvement on their haemopoetic status after receiving blood transfusion and a resultant increase in $\mathrm{Hb}$ to $\geq 7 \mathrm{gm} \%$.

Comprehensive abortion care (CAC) service was established in $18^{\text {th }}$ March, 2004 (chaitra 2059) two years after legalization of abortion in September 2002. Since then, this unit is providing services invariably to all the women demanding safe abortion service for pregnancy $\leq 12$ weeks; (necessitating accompaniment of guardians for adolescents under 16 years). In selected cases up to 18 weeks of gestation where pregnancy occurred after rape or incest or in any case where the continuation of pregnancy was a threat to maternal well being. This center unlike PAC Unit is open only during the day (9am - 4pm) and handles 1015 cases on an average per day maximum up to 30 cases. This study aimed to find out if the number of women coming with abortion related complication has decreased after the inception of CAC services with special references to induced abortions.

\section{Methods}

Retrospective study carried in both the PAC /CAC Centre at Prasutigirha Hospital, Thapathali starting from their period of inception, May $1995 /$ March $18^{\text {th }}$ 2004 until February 2007, authenticating the number of cases received and complications faced.

\section{Results}

CAC Unit from March 18, 2004 - Feb.15, 2007 (Chaitra $\left.5^{\text {th }} 2059-2063\right)$ screened 12481 women out of which $2861(23 \%)$ were not provided the service for various reasons. These cases were sent back as the pregnancy was negative or when the pregnancy was beyond 12 weeks of gestational age. In total 9620 women ( $77 \%$ of the total screened), were served. Offering $11 \%$ of national coverage of total 85,984 CAC clients served since legalization of abortion service in the whole country. Special cases dealt by this center were rape (13) or incest (2), HIV (4) along with various cases of medical disorders of pregnancies (23). (Table1)

Complications at the center were 198/9620 (2\%). Complications that arose were shock, drug allergy, infection, ectopic pregnancy and continuation of pregnancy. Of them $20(0.02 \%)$ were due to uterine perforation (Table.2). Out of this, 10 who needed laparotomy required hospitalization.

PAC Unit from 28th May1995 - April 2007 has served 19325 women [D\&C (7806) and MVA (11519)] which formed $43.8 \%$ of total gynaecological admission and $91.84 \%$ of the total 21043 abortion related cases (Table 3).

In the last 10 year period, 11519 cases were dealt in this MVA unit, the number of intra/post procedural complications are within $6 \%$.

Overall complications of CAC Unit were much less in comparison to PAC Unit as far as MVA was considered, a method of procuring abortion in these 2 units. At the same time nature of complications was more morbid in CAC Unit involving uterine perforation. Intraprocedural complications in $\mathrm{CAC}$ and PAC Unit

Tablel. CAC services provided in special cases

\begin{tabular}{|c|c|}
\hline \multicolumn{2}{|c|}{ Unusual circumstances } \\
\hline - Rape - & 13 \\
\hline - Incest - & 2 \\
\hline \multicolumn{2}{|c|}{ Medical disorder of pregnancy } \\
\hline - Heart disease - & 13 \\
\hline - Jaundice - & 3 \\
\hline - Hypertension - & 2 \\
\hline - HIV + ve - & 4 \\
\hline - Leukemia - & 1 \\
\hline
\end{tabular}


Table 2: Complications in PAC and CAC Unit

\begin{tabular}{|c|c|c|c|c|}
\hline \multirow[t]{4}{*}{ Time } & \multirow[t]{2}{*}{ Type of complications } & CAC & \multicolumn{2}{|c|}{ PAC } \\
\hline & & $061-063$ & $061-063$ & 1995-2007 April \\
\hline & & $3 y r s$ & $3 y r s$ & 10 years \\
\hline & & $N=9620$ & $N=2419$ & $N=11519$ \\
\hline \multirow{6}{*}{$\begin{array}{l}\text { During } \\
\text { procedure }\end{array}$} & Uterine perforation & $20(0.20 \%)$ & - & 00 \\
\hline & Shock & 00 & 19 & 53 \\
\hline & Difficult/Os dilatation & 00 & 1 & 5 \\
\hline & Cervical Injury & 00 & 1 & 5 \\
\hline & Hemorrhages & $10(0.10 \%)$ & $56(2.3 \%)$ & $127(1 \%)$ \\
\hline & failed MVA & 00 & $86(3.5 \%)$ & 243 \\
\hline Total* & & $30(0.3 \%)$ & $163(6.7 \%)$ & $433(3.75 \%)$ \\
\hline \multirow{3}{*}{$\begin{array}{l}\text { After } \\
\text { procedure }\end{array}$} & Incomplete MVA & $116(1.2 \%)$ & 110 & $214(1.86 \%)$ \\
\hline & infection/ Sepsis/PID & $26(0.27 \%)$ & 1 & $6(0.05 \%)$ \\
\hline & Pregnancy continuation & $26(0.27 \%)$ & 00 & 1 \\
\hline Total $* *$ & & $168(1.75 \%)$ & $111(4.5 \%)$ & $221(1.9 \%)$ \\
\hline$*+* *$ total & & $198(2.05 \%)$ & $274(11.3 \%)$ & $654(5.67 \%)$ \\
\hline
\end{tabular}

were $0.3 \%$ and $3.75 \%$ ). Hemorrhage occurred in $0.1 \%$ in CAC and $1 \%$ in PAC. Post procedural complications in CAC Unit as incomplete evacuation was $1.2 \%$ and $1.86 \%$ in PAC Unit. But the infection/sepsis or pelvic inflammatory diseases (PID) were much lesser in PAC Unit, which is surprising (Table 2).

Comparing the total number of MVA: 11, 519 PAC cases with 9, $620 \mathrm{CAC}$ cases, it is found that the total percentage of complications was much more higher in PAC Unit (Table2).

This is $5.75 \%$ against $2 \%$ in CAC.

Among all the complication, hemorrhage and shock were more frequently seen in PAC Unit. Whereas, the number of uterine perforation were more annoyingly high in the CAC unit seen in 20 cases. Sepsis and PID were less in PAC compared to CAC and this is a very important finding.

Table 3. PAC services over 10 years

\begin{tabular}{|lrr|}
\hline Total Gyn admission & 44077 \\
Abortion related admission & 21043 \\
Total PAC cases & 19325 \\
D \& C & $(40 . \% / 19325)$ & 7806 \\
MVA & $(59.6 \%$ of 19325$)$ & 11519 \\
$\begin{array}{l}\text { Conservative management } \\
\text { of abortion }\end{array}$ & $(8.16 \%)$ & 1718 \\
\hline
\end{tabular}

PAC in the years 2058-2060/ 2061 -2063: preceding and recent three years after inception of CAC Unit.

Concentrating on 3 years period 2058 - 2060 [April 2001- 2004 April] PAC clients in each consecutive years were seen to rise 1217, 1333 and 1409 to a total of 3959. But the MVA figures in these years were provided to 618,701 and 646 (fig 1) to a total of 1965.

There has been continuous rise in the number of PAC clients during 2060-63 (April 2004- 2007 April) figures available for these years obtained as 1396, 1446 and 1481 to a total of 4323. MVA service provided for PAC clients in these three years were 709,809 and 901 to a total of 2419.

Going back to Table 2 for comparative complications in the recent years, PAC Unit still had more complications. But the seriousness of complications was more in CAC unit in reference to uterine perforation.

Even the total percentage of complication comparing these two units for the period of recent three years after CAC unit was operational, noted much higher complications in PAC i.e. $11.3 \%(274 / 2419)$ versus $2 \%$ (198/9620) for CAC.

Total number of actual cases of induced abortion was 354 [(163 in (2058-2060) or 191 in (2061-2063). This is because of yearly rise in the total number of induced abortion cases which varied between 55- 71 annually. The total hospital figure of numbers of induced 
abortion cases in the 6 years period is focused in Table 4 ; which is seen to be increasing in all the years except the year 2060 .

Percentages of induced cases out of total PAC cases (including both the MVA and D\&C) for each consecutive years: $2058-2063$ were $4.5 \%$ (55/1217), $4.2 \%$ (59/1333), 3.5\% (49/1409) and 4\% (57/1396), $4.7 \%$ (71/ 1446), $4.2 \%$ (63/1481). This shows $12.2 \%$ of induced cases in the preceding 3 years before CAC services and $12.9 \%$ during the years of CAC services which in comparison is almost alike.

The total number of induced abortion in recent/ preceding 3 years was 191: 163 which beyond doubts has shown a significant increase in the decline of the total number of more complicated cases of induced abortion from 52 to 34 (table 4). On the positive side was a $50 \%$ decrease in the complicated cases of induced abortion ( 9 cases in the year 2063 compared to 2058.

Even the number of septic shock came down to 7 from 24 in the past 3 years (Table 4).

There were as many as 37 cases of uterine perforation which included peritonitis due to perforated appendix (1) and bowel perforations (4). Unfortunately, a rise in the number of uterine perforation during $2061-2063$ (9), almost 4 times higher than the values in the preceding 3 years is seen (8: 29). If 10/29 cases were from the CAC unit of Prasutigirha, the rest of the 19 cases must have come from other places.

PAC unit also came across ectopic (4), H. Mole (5) and choriocarcinoma (1) which were worthy of record.

\section{Discussion}

It must be remembered that the number of women coming to avail CAC services were almost four times of those coming for PAC services (9620: 2419) Table 2. Total client received at CAC Unit was 12481 out of which 9620 were really served. This number is higher even when figures for 6 years of PAC services when put together; a sum total 8282[2058-2060 (3959) + 20612063 (4323)].

Abortion related cases seemed to be slightly below $50 \%$ of the general gynecological admission. Were it not for CAC services, the number of PAC cases would have definitely gone much higher. One can speculate the reduction in the number of more complicated cases of induced abortion recently due to the inception of CAC service in the country.

Incomplete abortions were both seen in PAC and CAC service with few exceptions of molar and choriocarcinoma cases, which were carefully diagnosed post manual vacuum aspiration at PAC unit. With this finding, more emphasis must be laid on the careful conduct of uterine evacuation completely, such that

Table 4. Seriously complicated induced abortion out of the total induced abortion cases.

\begin{tabular}{|lccccccc|}
\hline \multicolumn{2}{|c}{$\mathbf{2 0 5 8}$} & $\mathbf{2 0 5 9}$ & $\mathbf{2 0 6 0}$ & $\mathbf{2 0 6 1}$ & $\mathbf{2 0 6 2}$ & $\mathbf{2 0 6 3}$ & Total \\
\hline Total number of induced Abortion in hospital admission & $\mathbf{5 5}$ & $\mathbf{5 9}$ & $\mathbf{4 9}$ & $\mathbf{5 7}$ & $\mathbf{7 1}$ & $\mathbf{6 3}$ & $\mathbf{3 5 4}$ \\
\hline Complicated septic induced Abortion in hospital admission & $\mathbf{1 8}$ & $\mathbf{1 8}$ & $\mathbf{1 6}$ & $\mathbf{1 4}$ & $\mathbf{1 1}$ & $\mathbf{9}$ & $\mathbf{8 6}$ \\
\hline Septic shock & 11 & 9 & 4 & 2 & 3 & 2 & $\mathbf{3 1}$ \\
Septic ARF & 1 & 1 & - & - & 1 & - & $\mathbf{3}$ \\
Haematuria & - & - & - & 2 & - & - & $\mathbf{2}$ \\
Hb $<$ gm\% & 4 & 7 & 4 & 4 & 2 & 5 & $\mathbf{2 6}$ \\
DIC & 1 & 1 & - & - & - & - & $\mathbf{2}$ \\
Ut perforation & 2 & 1 & 4 & 7 & 12 & 10 & $\mathbf{3 6}$ \\
Ut perforation \& ruptured appendix & 1 & - & - & - & - & - & $\mathbf{1}$ \\
Bowel perforation & - & 1 & 1 & 1 & - & 1 & $\mathbf{4}$ \\
Peritonitis & - & 1 & 1 & 1 & - & 1 & $\mathbf{4}$ \\
\hline Total & $\mathbf{2 0}$ & $\mathbf{2 1}$ & $\mathbf{1 6}$ & $\mathbf{1 5}$ & $\mathbf{1 8}$ & $\mathbf{1 9}$ & $\mathbf{1 0 9}$ \\
\hline
\end{tabular}

NB: Since a single woman could have one or more complication, the total number given in the bottom does not tally to the exact number of complicated induced, abortion cases. 
there is either no incomplete procedure or complete procedure without uterine perforation.

A short review of complicated post abortion cases admitted to this Maternity Hospital, just after the legalization of abortion has given some insight to induced abortion, which was performed at $\geq 12$ weeks in $39 \%$. The most common reason for seeking abortion was too many children (59\%) followed by illegitimate pregnancy $(16 \%)$. Twenty-one cases of induced abortion were performed by doctors and the commonest method used was D\&C (75\%). Incomplete abortion was quite significant i.e. $77 \%$ of which 20 underwent evacuation under sedation while five were treated by MVA. There was documentation of a case of uterine perforation, bowel injury and peritonitis requiring laparatomy. ${ }^{4}$

Complications in CAC Unit with $0.02 \%$ rate of uterine perforation is within acceptable limit within such a huge number. However the rate of uterine perforation was at immense rise as a sequel to induced abortion (fig1). As a matter of fact bowel perforation is not as high as reported from one of the Post Graduate Medical Institution where 11 such cases of injuries inflicted were treated in two year period. ${ }^{5}$ One mortality was reported shortly after resection and end to end anastomosis surgery and the other many days later from fecal fistula formation in a medical institution. ${ }^{6-7}$
Death has resulted both from hemorrhagic and other septic sequel. ${ }^{8,9}$ However in our CAC center, there have been no cases of mortality till date which is inspiring. Presently, there has been concern over the rise in number of uterine and bowel perforations in our hospital, which to some extent is attributed by the CAC unit.

PAC unit always has been known for its client's satisfactions. These were assessed in a prospective study conducted during 12 months in 1998, where 529 treated in the MVA unit and 236 who were clinically eligible for treatment in the MVA unit but were treated instead in the main operation theatre (OT). MVA client had fewer complaints and were generally more satisfied with the services they had received than their counterparts. ${ }^{10,11}$ Even the CAC Unit has commendable contraceptive acceptance of $90 \%$.The functions of both PAC and CAC Units have been complementary to each other with similar kind of family planning acceptance of $90-92 \%$ now and before.

Some of the CAC centers have been working hard to make women accept them in a right way. ${ }^{12}$ With legalization of abortion; women take abortion as other means of family planning. This must be discouraged. Teenage adolescents are careless about contraception and at liberty to choose pregnancy terminations. ${ }^{13} \mathrm{At}$ this point one must remember, however safe CAC is,

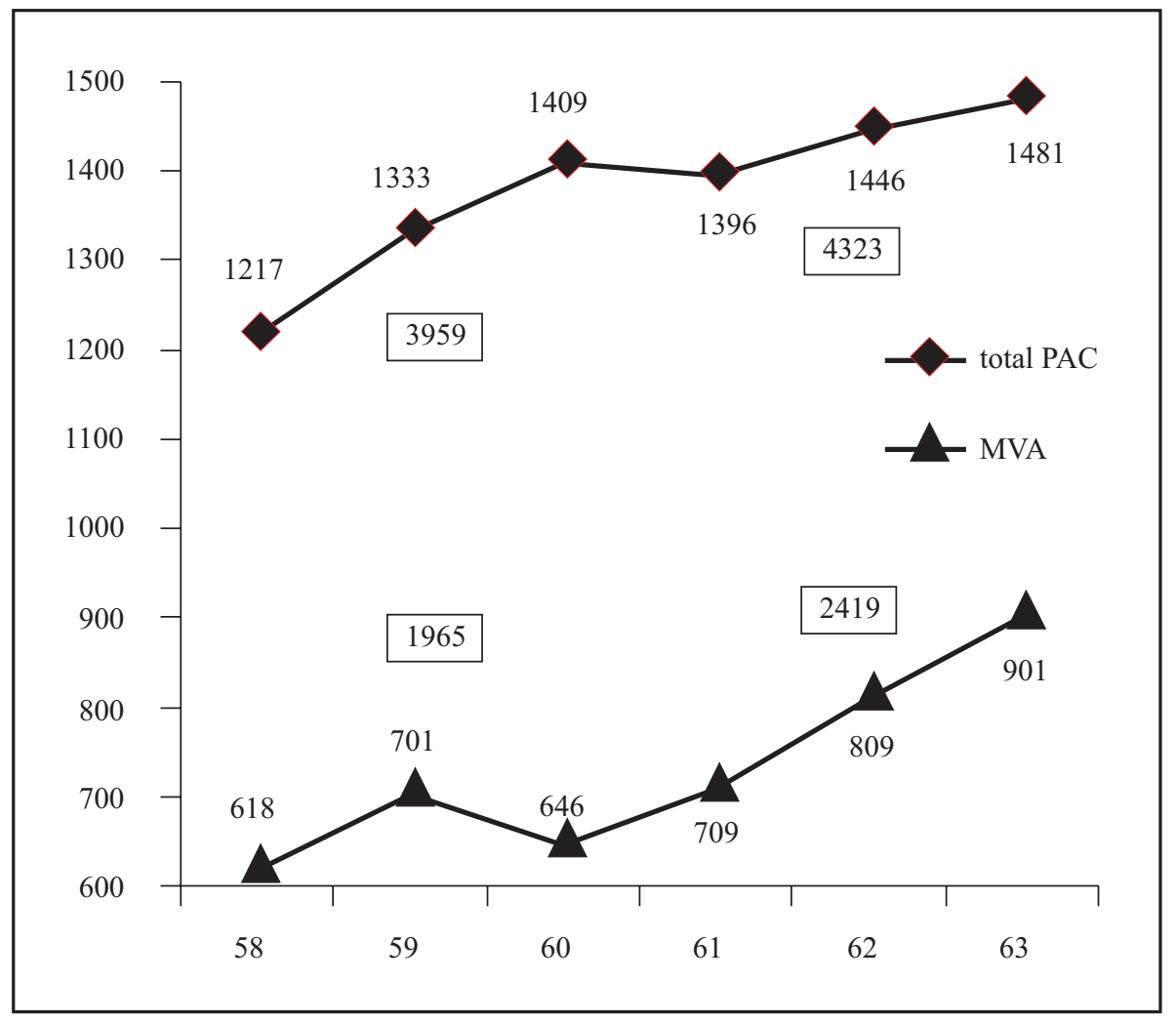

Figl. PAC/MVA 


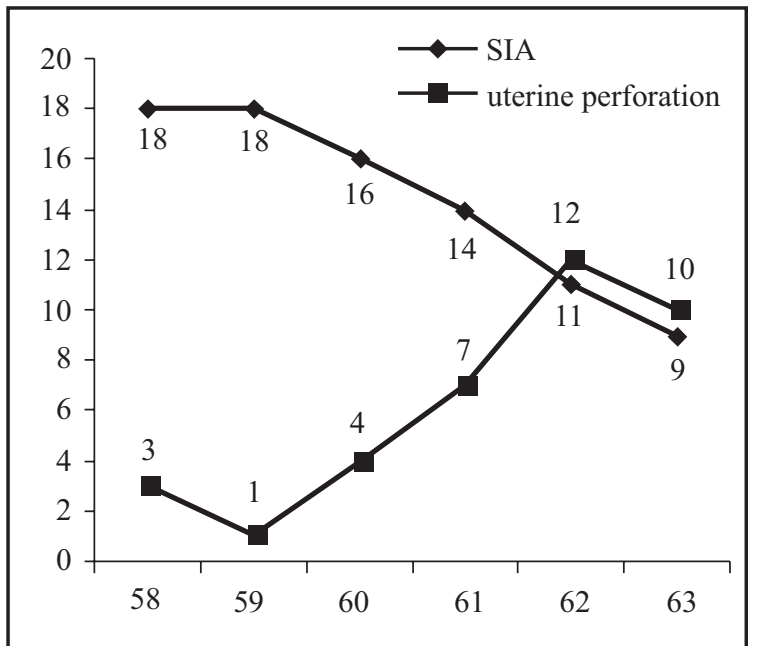

Fig 2. SIA/Uterine perforation

yet few women are seen to have complications even from safe abortions services. Therefore it is better to avoid an unwanted pregnancy than undergo an intervention and be exposed to the risks of operative procedures. However minor they may be, complication after all is morbidity.

\section{Conclusion}

Current scenario has indicated many women coming for safe abortions care service which is almost three times the post abortion care service, showing a little rise in the cases of uterine perforation than the three years before CAC service had been introduced.

\section{Acknowledgement}

We humbly would like to acknowledge our thanks to Jaya Poudel, Leena Maharjan, Biru Maharjan, Shakun Thapa involved in CAC and PAC unit.

\section{References}

1. Rao KA, Faúndes A. Access to safe abortion within the limits of the law. Best Pract Res Clin Obstet Gynaecol. 2006 Jun; 20(3):421-32. Epub 2006 Mar 24.

2. Adesiyun AG, Ameh C.An analysis of surgically managed cases of pelvic abscess complicating unsafe abortion. J Ayub Med Coll Abbottabad 2006 Apr-Jun; 18(2):14-6
3. Healy J, Otsea K, Benson J. Counting abortions so that abortion counts: Indicators for monitoring the availability and use of abortion care services. Int J Gynaecol Obstet. 2006 Nov; 95(2):209-20. Epub 2006 Oct 5.

4. Ojha N, Sharma S, Paudel J. Kathmandu Univ Med J (KUMJ). Post legalisation challenge: minimizing complications of abortion 2004 Apr-Jun; 2(2): 131-6.

5. Jhobta RS, Attri AK. Jhobta A. Bowel injury following induced abortion. Int J Gynaecol Obstet. 2007 Jan; 96(1):24-7. Epub 2006 Oct 27.

6. Rana A, Pradhan N, Gurung G, Singh M. Induced septic abortion: a major factor in maternal mortality and morbidity. J Obstet Gynaecol Res 2004 Feb; 30(1):3-8.

7. Pokharel SM. Sharma J. Sharma SP. Septic induced abortion claiming life of a Nepalese woman. JNMA J Nepal Med Assoc. 2005 OctDec; 5844(160):152-5.

8. Sharma M, UpretyD Pokhrel M, Karki A, Sharma U, Babu S. Maternal mortality at B P Koirala Institute of Health Sciences, Nepal: review of 6 years. Trop Doct 2005 Jan; 35(1):25-6

9. Padhye SM, Lakhey B. "Brought Dead" - cases of maternal mortality. Kathmandu Univ Med J (KUMJ). 2003 Jul-Sep: 1(3):184-6

10. Thapa S, Poudel J, Padhye S.Triaging patients with post-abortion complications: a prospective study in Nepal. J Health Popul Nutr 2004 Dec; 22(4):383-98.

11. Billings DL, Benson J. Postabortion care in Latin America: policy and service recommendations from a decade of operations research. Health Policy Plan 2005 May; 20(3):158-66.

12. NguyÅn MH, Gammeltoft T, Rasch V. Situation Analysis of Quality of Abortion Care in the Main Maternity Hospital in Hai Phòng, Viet Nam. Reprod Health Matters. 2007 May; 15(29): 172-182

13. Harvey N, Gaudoin M. Teenagers requesting pregnancy termination are no less responsible about contraceptive use at the time of conception than older women BJOG. 2007 Feb; 114 (2): 226-9. 